\title{
APLICABILIDADE DE FLORAIS DE BACH COMO TERAPIA ALTERNATIVA
}

\author{
APPLICABILITY OF BACH FLOWERS AS AN ALTERNATIVE THERAPY \\ Vanessa de Miranda Narde Vieira ${ }^{1}$ \\ Michel Santos da Silva ${ }^{2}$ \\ Leonardo Guimarães de Andrade ${ }^{3}$ \\ Lívia Cabral Lobo ${ }^{4}$
}

RESUMO: A busca por uma melhor qualidade de vida é inerente do ser humano. De acordo com a Organização Mundial da Saúde (OMS) a procura por tratamentos alternativos e com menos efeitos danosos tem aumentado nos últimos anos. O uso de florais nas terapias alternativas visa ampliar as oportunidades de tratamento, trazendo resultados mais satisfatórios através do reequilíbrio das emoções e do realinhamento dos aspectos físicos e energéticos, promovendo um tratamento mais holístico. A pesquisa foi realizada através da metodologia de revisão de literatura, foram apurados dados por meio artigos, monografias, dissertações, teses, manuais governamentais e sites relevantes. Objetiva-se nesse estudo conhecer sobre as várias indicações do uso das i76fetividad florais e analisar sobre a sua efetividade nas terapias alternativas.

Palavras-chave: Terapia Floral. Floral De Bach. Terapia Alternativa. Farmacêutico.

ABSTRACT: The search for a better quality of life is inherent to the human being. According to the World Health Organization (WHO) the search for alternative treatments with less harmful effects has increased in recent years. The use of flower essences in alternative therapies aims to expand treatment opportunities, bringing more satisfactory results through the rebalancing of emotions and realignment of physical and energetic aspects, promoting a more holistic treatment. The research was carried out through the literature review methodology, data were collected through articles, monographs, dissertations, theses, government manuals and relevant websites. The aim of this study is to know about the various indications for the use of flower essences and analyze their effectiveness in alternative therapies.

Keywords: Floral Therapy. Bach Floral. Alternative Therapy. Pharmaceutical.

\footnotetext{
I Discente do curso de farmácia pela UNIG - Universidade Iguaçu, Curso de Graduação em Farmácia, Nova Iguaçu-RJ, Brasil.

${ }^{2}$ Docente do curso de farmácia pela UNIG - Universidade Iguaçu, Curso de Graduação em Farmácia, Nova Iguaçu-RJ, Brasil.

${ }_{3}^{3}$ Docente do curso de farmácia pela UNIG - Universidade Iguaçu, Curso de Graduação em Farmácia, Nova Iguaçu-RJ, Brasil.

${ }_{4}$ Mestre, professora e orientadora do curso de farmácia pela UNIG - Universidade Iguaçu, Curso de Graduação em Farmácia, Nova Iguaçu-RJ, Brasil.
} 


\section{INTRODUÇÃO}

A busca por uma melhor qualidade de vida é inerente do ser humano, diante disso é crescente a demanda por tratamentos mais naturais, com menor impacto de reações adversas, seja para obter uma melhoria na qualidade do sono ou ter mais qualidade nas relações interpessoais e profissionais (BRAGA et al., 2018).

De acordo com a Organização Mundial da Saúde (OMS) a procura por tratamentos alternativos tem aumentado nos últimos anos, as Práticas Integrativas e Complementares (PICs) são terapias alternativas que se correlacionam com a atenuação da dor e do estresse, melhora na qualidade do sono, redução da tensão muscular e melhoria na imunidade (FERREIRA, 202I)

As PICs são a consolidação da cultura de saberes circulantes na sociedade que por sua vez atuam na promoção e cuidado da saúde, bem como na prevenção e desenvolvimento terapêutico, integrando o ser humano ao meio ambiente. As PICs Fazem parte da Política Nacional de Práticas Integrativas e Complementares (PNPIC) e foram institucionalizadas no Sistema Único de Saúde (SUS) através da Portaria GM/MS no 971/2006, já a terapia com florais só foi inclusa em 2018, através da Portaria no 702/2018 (SANTOS, TESSER, 2012; ANTONIO, TESSER, MORETTI-PIRES, 2013; BRASIL, 2017).

A Terapia Floral (TF) faz parte das PICs e é obtida a partir da essência de flores, árvores, folhas, plantas silvestres, esse tratamento natural tem por intuito complementar o tratamento medicamentoso, atuando na harmonização e equilíbrio dos sentimentos (BRAGA., 2018).

Os florais de Bach, são considerados instrumentos de cura não invasivas, são compostos por 38 essências mais o Rescue Remedy e foram criados pelo médico inglês Edward Bach por volta da década de 30. Seu uso é reconhecido em mais de 50 países e foi aprovado pela OMS em meados da década de 50 (DE-SOUZA, 2006; INSTITUTO BACH, 2020)

Esse estudo tem como perspectiva conhecer sobre as várias indicações do uso da afetividade florais e analisar sobre a sua efetividade nas terapias alternativas. 


\section{I. OBJETIVO}

Identificar a aplicação dos florais de Bach como complemento nas terapias alternativas.

\subsection{OBJETIVOS ESPECÍFICOS}

- Explanar o surgimento das terapias florais;

- Detalhar as principais indicações dos florais de Bach;

- Analisar a 178 fetividade dos florais nos tratamentos alternativos;

- Descrever a atuação do farmacêutico na terapia com florais.

\section{MÉTODOLOGIA}

Para o desenvolvimento dessa pesquisa, foi utilizado método qualitativo, por meio de revisão literária, utilizando materiais extraídos das bases de dados: Google Acadêmico, SciELO - Scientific Eletronic Library, periódicos, monografias, congressos, legislações, dissertações, e materiais do Ministério da Saúde (MS) que datam do ano de 2005 a 202I. De modo descritivo, como critério de inclusão foram pré-definidos os materiais em idioma português, inglês e espanhol, artigos que descreviam sobre a aplicação dos florais de Bach nos tratamentos complementares. Os critérios de exclusão utilizados foram eliminar os artigos de outras línguas estrangeiras não mencionadas e aqueles que estavam fora do período escolhido.

\section{JUSTIFICATIVA}

Justifica-se com esse trabalho analisar a contribuição dos florais como recurso terapêutico, entender e detalhar suas aplicações, além de descrever como o profissional farmacêutico pode atuar como conhecedor técnico da terapia à base de essências florais.

\section{REVISÃO DE LITERATURA}

\section{I SURGIMENTO DA TERAPIA COM FLORAIS}

A terapia com florais teve como pioneiro o médico inglês Edward Bach, o qual deu origem aos florais que levam seu nome, o conhecimento de Bach levou a pesquisadores de 
vários lugares do mundo a produzirem seus próprios florais, hoje já se tem conhecimento dos Florais da Califórnia, Florais de Saint-Germain. Aqui no Brasil temos os Florais do Planalto Central, de Minas, da Amazônia, da Mata Atlântica e de vários outros lugares. Os quais tem o mesmo objetivo, a partir das essências das plantas, intervir no desequilíbrio vibracional do organismo (AZIZ., 2020).

A Associação Brasileira de Farmacêuticos Homeopáticos, define essência floral como um tratamento suplementar para a saúde, preparado a partir de flores e outras partes de vegetais, minerais e radiações de ambientes, adquiridos por meio de extração solar, ambiental ou decocção, seguido de diluição (ASSOCIAÇÃO BRASILEIRA DE FARMACÊUTICOS HOMEOPÁTICOS, 2009).

Os florais resultam das experiências e conhecimentos adquiridos por seus pesquisadores, com a mesma essência do Dr. Bach, que representava a alma humana em cada essência. Desta forma cada região produz florais com elementos extraídos da sua própria localidade, por exemplo, no Alasca, Steve Johnson, extrai da natureza intocável essências de aceleração e frequência que agem como revitalizantes, já na Austrália, através do conhecimento aborígene, os florais produzidos por Ian White trazem vigor ao indivíduo que as utiliza (BENKO et al., 2004).

Os florais quânticos têm suas ações centradas na energia vital. Não dispõem de princípios ativos, porém são capazes de se conectar às células através de energia eletromagnética. Nossas células são estimuladas e reagem de maneira epigenética. A epigenética é a ciência que estuda as mudanças nas funções dos genes, sem alterar o sequenciamento do DNA (ZAMBONATO., 2020).

Os mais de 80 florais de Saint Germain criados por Neide Margonari, foram constituídos através de flores brasileiras, os quais, por meio do campo físico, ajudam a atenuar diversos males como: cólicas no fígado, diabetes, dificuldade de dormir, úlcera gástrica, tuberculose pulmonar, diabetes. Sobre o campo emocional, mental e espiritual agem sobre os medos, depressão, estresse e traumas (SALGADO., 2010). Para Scheffer a cura provém do perfeito equilíbrio entre todos os sistemas contidos em seu interior, o tratamento 
baseado na forma holística, integrando corpo, alma e espírito é capaz de transmitir uma mensagem única em cada ser, essa mensagem é o verdadeiro processo de cura (SCHEFFER, 2008).

Bach acreditava que era preciso curar os pacientes e não a doença, onde a desarmonia entre corpo e mente era capaz de adoecer o indivíduo. Estimulados por essa filosofia, profissionais tem estudado as terapias com florais, a fim de ter um olhar mais humanístico para o processo de saúde-doença (SANCHES et al, 2016).

\subsection{FLORAIS DE BACH}

Edward Bach foi um médico inglês, que mais precisamente em 1928 criou a terapia com florais, denominada então de florais de Bach. Ele dedicou a sua vida aos estudos, onde tentava correlacionar que a saúde e a doença estavam ligadas intrinsicamente com a forma que cada pessoa reagia aos mais diversos meios (SALES, 2012).

Os florais de Bach são provenientes de plantas silvestres, flores e árvores do campo, atuam de forma que harmonizam os sentimentos, ao substituir a negatividade pela positividade, propiciando melhor qualidade de vida, podendo ser utilizados em conjunto com qualquer outro tratamento, por esse motivo é chamado de terapia complementar (PANCIERI et al, 2018).

Os florais não possuem toxicidade, nem causam dependência ao paciente que opta pela utilização em seu tratamento. A descoberta dos florais, via de regra tem como função tratar e equilibrar a mente diante dos conflitos, e por consequência oferecer cura e melhorar a qualidade de vida do paciente, visto que uma mente serena e sem confusões, se cura mais rápido em menos tempo (BEAR et al., 2005).

Segundo Bach, possuímos dois componentes: alma e personalidade, das quais a imortalidade e caráter transitório, são respectivamente as características desses componentes, que necessitam estar em equilíbrio, e é nesse âmbito que as terapias alternativas com florais interveem, visando um cuidado holístico, por meio do 
fortalecimento entre profissional, aqui em destaque o farmacêutico e o paciente (GALLI et al., 2012).

\subsection{INDICAÇÕES DO USO DE FLORAL DE BACH}

CARTER (2012) relata que entre 1928 e 1932, Bach criou o primeiro grupo de florais e os chamou de os Doze Curadores. Segundo ele cada floral descrevia estados emocionais positivos e negativos a qual demonstra os sentimentos vivenciados por uma pessoa quando está com boa saúde, e quando necessita de floral. No quadro i será apresentado os Doze Curadores e suas aplicabilidades nas terapias alternativas.

QUADRO I: DOZE CONDIÇÕES EMOCIONAIS E SEUS RESPECTIVOS

\section{FLORAIS}

\begin{tabular}{|c|c|c|}
\hline Estado de ânimo negativo & Planta do floral & Estado de ânimo positivo \\
\hline Impaciência & Impatiens & Ritmo \\
\hline Medos concretos/ Timidez & Mimulus & Segurança/Empatia \\
\hline Indiferença/Dispersão & Clematis & Foco/Ancoramento \\
\hline Felicidade aparente & Agrimony & Paz interior \\
\hline Possessividade/Autopiedade & Chicory & Amor incondicional \\
\hline Entusiasmo exacerbado & Vervain & Respeito à opinião alheia \\
\hline Vontade enfraquecida & Centaury & Força e poder interior \\
\hline Insegurança & Cerato & Confiança na intuição \\
\hline Indecisão & Scleranthus & Determinação \\
\hline Alienação/Orgulho & Water violet & Envolvimento/servir ao próximo \\
\hline Dúvida devido à falta de fé & Gentian & Perseverança \\
\hline Terror & Rock rose & Coragem \\
\hline
\end{tabular}

FONTE: (CARTER, 2012)

No que se refere a sua aplicabilidade, a terapia floral de Bach possui 38 essências, divididas em 7 classes: (a) para os que tem medo, (b) para indecisão, (c) para falta de interesse pelas circunstâncias atuais, (d) solidão, (e) para sensibilidade excessiva a 
influências e opiniões alheias, (f) para quem está desesperado e abatido, (g) preocupação excessiva com o bem estar dos outros (VARGAS, 2019).

TABELA r: ESSÊNCIAS DE BACH E SUAS APLICABILIDADES NAS EMOÇÕES

\begin{tabular}{|c|c|c|}
\hline Sintomas Emocionais & Tipo de Flores & Espécie de Flores \\
\hline $\begin{array}{l}\text { Para os que sentem } \\
\text { medo. }\end{array}$ & $\begin{array}{l}\text { Flores que trazem } \\
\text { encorajamento para } \\
\text { realizar desde as aços } \\
\text { mais simples do } \\
\text { cotidiano e ate os } \\
\text { enfrentamentos mais } \\
\text { desafiantes. }\end{array}$ & $\begin{array}{l}\text { Rock Rose, Mimulus, } \\
\text { Cherry Plum, Aspen, } \\
\text { Red Chestnut. (Figura 1) }\end{array}$ \\
\hline $\begin{array}{l}\text { Para os que sofrem de } \\
\text { indecisalo. }\end{array}$ & $\begin{array}{l}\text { Flores que trazem } \\
\text { assertividade, clareza } \\
\text { de proposito, vigor, } \\
\text { esperança, otimismo e } \\
\text { fe. }\end{array}$ & $\begin{array}{l}\text { Cerato, Scleranthus, } \\
\text { Gentian, } \\
\text { Hornbeam, wild Oat. }\end{array}$ \\
\hline $\begin{array}{l}\text { Falta de interesse pelas } \\
\text { circunstancias atuais. }\end{array}$ & $\begin{array}{l}\text { flores que trazem } \\
\text { presenca desperta e } \\
\text { focada no momento } \\
\text { presente, vivificada pela } \\
\text { alegria. }\end{array}$ & $\begin{array}{l}\text { Clematis, Honeysuckle, } \\
\text { Wild Rose, Olive, White } \\
\text { Chestnut, Mustard, } \\
\text { Chestnut Bud. (Figura2) }\end{array}$ \\
\hline Para a solidalo. & $\begin{array}{l}\text { Flores que ensinam a } \\
\text { compartilhar os proprios } \\
\text { dons, modulando os } \\
\text { ritmos pessoais, } \\
\text { favorecendo pess os } \\
\text { relacionamentos. }\end{array}$ & $\begin{array}{l}\text { Water Violet, Imp: } \\
\text { Heather. }\end{array}$ \\
\hline $\begin{array}{l}\text { Para os que tam } \\
\text { sensibilidade excessiva } \\
\text { as influéncias } \\
\text { opiniós. }\end{array}$ & $\begin{array}{l}\text { Flores que nos ajudam a } \\
\text { fazer transiçoes, atuar } \\
\text { com transpartencia e } \\
\text { seguir livre de } \\
\text { influencias limitadoras. }\end{array}$ & $\begin{array}{l}\text { Agrimony, Centaury, } \\
\text { Walnut, Holly. }\end{array}$ \\
\hline $\begin{array}{l}\text { Para o desalento } 0 \text { o } \\
\text { desespero. }\end{array}$ & $\begin{array}{l}\text { Flores que nos ajudam a } \\
\text { estabelecer vínculos por } \\
\text { meio da profunda } \\
\text { coragem da aceitaçäo } \\
\text { do outro e de nos } \\
\text { mesmos. }\end{array}$ & $\begin{array}{l}\text { Larch, Pine, Elm, Sweet } \\
\text { Chestnut, Star of } \\
\text { Bethlehem, Willow, Oak, } \\
\text { Crab Apple. }\end{array}$ \\
\hline $\begin{array}{l}\text { Excessiva preocupaçajo } \\
\text { com o bem-estar dos } \\
\text { outros. }\end{array}$ & $\begin{array}{l}\text { Flores que nos ajudam a } \\
\text { amar com compaixăo, } \\
\text { fluindo com tolerância } \\
\text { pelo "caminho do meio". }\end{array}$ & $\begin{array}{l}\text { Chicory, Vervain, Vine, } \\
\text { Beech e Rock Water } \\
\text { (sendo esta última a } \\
\text { unica essencia feita sem } \\
\text { infusalo de flor, apenas } \\
\text { com } \\
\text { potencializada). agua }\end{array}$ \\
\hline
\end{tabular}

FONTE: (BENKO et al., 2004). 
Os florais são uma das PICs mais utilizadas da atualidade, seu uso deve ser orientado por profissional especializado e apto a prescrição, de acordo com a necessidade de cada paciente, levando em conta sua doença, sinais e sintomas relatados. Os florais de Bach foram desenvolvidos por meio das experiências do próprio médico com outros profissionais, cirurgiões, cientistas e por intermédio de seus trabalhos com homeopatia e vacinas (VARGAS, 2019).

Nas terapias alternativas a utilização do floral tem por intuito agir no emocional, área ainda pouco abordada pela ciência, assim com o medicamento para depressão age nos sintomas, o floral age na área emocional do problema, seja medo, ansiedade, insegurança, pela qual muitas das doenças físicas se originam (OLIVEIRA., 2017).

No que diz respeito a sua finalidade nas terapias alternativas, os florais terapêuticos têm por princípios transformar os sentimentos e energias negativas em positivas. De acordo com AZIZ (2020), a padronização energética da flor ressoa na energia humana, reequilibrando as emoções ao seu estado original.

O desenvolvimento das terapias alternativas e complementares com uso de florais visa ampliar as oportunidades de tratamento, viabilizando resultados mais satisfatórios através do reequilíbrio das emoções através do realinhamento dos aspectos físicos e energéticos, promovendo um tratamento mais holístico (SILVA et al., 2013).

\subsection{ANÁLISE DA EFETIVIDADE DO USO DOS FLORAIS DE BACH COMO RECURSO TERAPÊUTICO NAS TERAPIAS ALTERNATIVAS}

Pelo fato das essências florais atuarem sobre o emocional do indivíduo, quando incluídas nas terapias alternativas, podem promover maior autocuidado, autonomia e efetividade em comparação a outros métodos de terapia holística (MACÍAS et al., 2012).

Revisões sistemáticas publicadas em 2009 e 2010 sobre a efetividade da terapia floral na ansiedade, tiveram respectivamente incluídas quatro e sete estudos clínicos controlados, 
e o resultado da maioria não mostrou eficácia da terapia floral em relação ao grupo placebo (THALER et al., 2009; ERNST, 2010).

Por outro lado, um estudo observacional conduzido por VEGA et al. (2012) verificou que o uso de essências florais se mostrou eficaz na atenuação da ansiedade, que levava os integrantes do estudo ao consumo excessivo de álcool, foram observados que após 30 dias e 6 meses com tratamento feito com floral de Bach houve menor chance de recaídas e diminuição dos sintomas de ansiedade, demonstrando que para esse grupo controle o uso de florais foi útil na diminuição da doença psicossomática, melhorando a qualidade de vida dos indivíduos.

Quanto às evidências da utilização dos florais de Bach no círculo vicioso entre violência, medo e trauma, os resultados mostraram uma redução considerável dessas emoções, ainda que em uma amostragem pequena, é sugerido mais estudos com mais participantes para comprovar essas ações (ALBUQUERQUE, 2016).

A utilização do uso de floral de Bach em um senhor de 78 anos com lesão de pele causada por Herpes Zoster, Diabetes Mellitus tipo II, em insulinoterapia, hipertenso e função renal prejudicada, sem apresentar bons resultados com as medicações alopáticas, obteve boa resposta clínica na diminuição da dor na lesão após $48 \mathrm{~h}$ da introdução da terapia floral, e em 8 semanas além da cura da lesão, foi verificado estabilidade em seu quadro clínico, demonstrando que de fato essa terapia alternativa pode auxiliar como coadjuvante no tratamento medicamentoso, realinhando corpo e mente (MARTINEZ \& GARRIDO, 2014).

Um estudo realizado por Albuquerque et al., (2016) com 17 crianças analisou o efeito dos florais nos traumas e medos em crianças que vivem em situação de pobreza, o qual teve por resultado uma melhora do grupo controle em relação ao grupo placebo, sugerindo que essa terapia pode auxiliar como tratamento nas sequelas que as emoções produzem no comportamento humano.

FERNÁNDEZ (20II) analisou o uso da Terapia floral de Bach em crianças com manifestações de hiperatividade, e o resultado demonstrou que houve melhora significativa 
na qualidade de vida das crianças e dos familiares, ressaltando a importância da implementação dessa terapia e sua divulgação para que mais famílias tenham acesso aos benefícios proporcionados.

MATOS \& GARCES (2014) pesquisaram sobre a efetividade da terapia floral em pacientes com hipertensão arterial fora de controle, e obtiveram resultados satisfatórios em pacientes com diversos graus de hipertensão, ressalta-se também a importância da realização de mais estudos e treinamentos, com intuito de promover maior conhecimento dos florais nas terapias alternativas, expandindo seu uso em outros problemas de saúde.

\subsection{ATUAÇÃO DO FARMACÊUTICO NA UTILIZAÇÃO DE FLORAIS}

A utilização da terapia com florais nas suas várias modalidades, é de exercício privado do Terapeuta Floral, profissional capacitado em cuidar da saúde através de uma abordagem naturalista, integrativa e alternativa, com ações que visam o equilíbrio entre indivíduo, meio ambiente e natureza (MOREIRA \& JUNQUEIRA, 2017).

Para que o farmacêutico possa utilizar dessa terapia nos tratamentos alternativos é necessária uma formação adequada para entender sua base científica, reconhecer a forma de atuação dessas essências florais, compreender a filosofia sobre o processo terapêutico, as formas de avaliar cada paciente e a escolha de cada essência e sua aplicação para cada doença (DOMENE, 2015).

Para o reconhecimento do farmacêutico como terapeuta floral, o profissional deve estar regularizado e obrigatoriamente inscrito no Conselho Regional de Farmácia de sua jurisdição, a Resolução no 6II, de 29 de maio de 2015, regulamenta a atuação do farmacêutico na Terapia Floral (CFF, 2017).

A resolução regulariza a atuação clínica do farmacêutico na terapia com essências florais e determina como exigências, para atuação na área, que o profissional tenha certificado de pós graduação lato sensu ou stricto sensu, reconhecido pelo MEC, ou no mínimo I8o horas de curso livre. Os farmacêuticos que comprovarem que já têm experiência na área, 
poderão requerer o reconhecimento, através da apresentação de termo de consentimento de atendimento a pelo menos dez pacientes, em um prazo de 12 meses (UNESC, 2015).

\section{CONCLUSÃO}

Conclui-se diante dos dados publicados a importância de se estudar sobre as terapias florais e suas aplicações nas diversas manifestações clínicas.

Ficou evidente nos estudos analisados que a utilização do floral de Bach tem contribuído significativamente como coadjuvante nos tratamentos medicamentosos, trazendo benefícios físicos e emocionais, além da melhoria da qualidade de vida dos pacientes.

Também foi possível compreender que a Terapia Floral pode ser utilizada pelo farmacêutico para auxiliar no processo de cura do paciente, à medida que ajuda a manter o equilíbrio das emoções. Assim o trabalho do farmacêutico com as essências tem por intuito

se unir ao trabalho de outros profissionais de saúde proporcionado um cuidado holístico para com o paciente, a sociedade e a saúde pública.

\section{REFERÊNCIAS BIBLIOGRÁFICAS}

Associação Brasileira de Farmacêuticos Homeopáticos. Manual de normas técnicas para o preparo de essências florais. São Paulo: SK; 2009

ALBUQUERQUE, Lucia Maria N. F. et al. Avaliando o efeito das essências florais nos traumas e medos em crianças que vivem em situação de pobreza. Cad. naturol. terap. Complem, v. 5, n. 8, p. 13-20, 2016

AZIZ, A. CADERNO DE ESSÊNCIAS FLORAIS. 2020

ANTONIO, Gisele Damian; TESSER, Charles Dalcanale; MORETTI-PIRES, Rodrigo Otávio. Contribuições das plantas medicinais para o cuidado e a promoção da saúde na atenção primária. Interface (Botucatu), Botucatu, v. 17, n. 46, p. 615-633, 2013. 
BEAR, J. BELLUCCO, W. FLORAIS DE BACH - O LIVROS DAS FÓRMULAS. I Ed. 2005 .

BRAGA, E. RAMOS, B. FUSCO, S. PANCIERI, A. SIGNIFICADOS DA TERAPIA FLORAL PARA ANSIEDADE EM PESSOAS COM SOBREPESO OU OBESIDADE. 2018.

BRASIL. Ministério da Saúde. Portaria de Consolidação n. 2, de 28 de setembro de 2017, Anexo XXV - Política Nacional de Práticas Integrativas e Complementares no SUS PNPIC-SUS, 2017. Disponível em: https://bvsms.saude.gov.br/bvs/saudelegis/gm/2017/ prcooo2_03_IO_2017.html

CFF - Resolução CFF no 6Ir, de 29 de maio de 2015. Dispõe sobre as atribuições clínicas do farmacêutico no âmbito da floral terapia, e dá outras providências. Disponível em: https://www.cff.org.br/userfiles/file/guia\%2opr\%C3\%Artico\%2odo\%2ofarmac\%C3\%AA utico\%2omagistral_o8dez2017_WEB.pdf. Acesso em: 30 de agosto de 2021.

CARTER R. Aprenda a Usar Florais de Bach. São Paulo: Healing herbs; 2012.

ERNST E. Bach flower remedies: a systematic review of randomised clinical trials. Swiss Med Wkly 2010. V.140, n.13079

FERNANDEZ, Sureima C. Bach flower therapy in children with hyperactivity manifestations. Medisan, 20II, v. 15, n. I2.

FERREIRA P. et al. Uso das práticas integrativas e complementares pela enfermagem em pessoas com câncer: revisão integrativa. Revista Brazilian Journal of health Review. v.4, n.I, p I84I-I858 jan./fev. 2021. https://doi.org/I0.34II9/bjhrv4nI- I50

GALLI KSB, Scaratti M, et al. Saúde e equilíbrio através das terapias integrativas: relato de experiência. Rev Enferm. 2012; v.8, n.8, p.245-255 
INSTITUTO BACH. Rescue remedy. 2020. Disponível em: http://institutobach.com.br/site/ conteudo/pagina/r,I8+Rescue.htm. Acesso em 3008 202I OLIVEIRA, L. CARISSIMO, T. ESTUDO DA EFICÁCIA DA TERAPIA FLORAL EM ALUNOS SUBMETIDOS A ESTRESSE. 2017

PANCIERI, A. P., FUSCO, S. B., RAMOS, B. I. A., \& BRAGA, E. M. Meanings of flower therapy for anxiety in people with overweight or obesity. Revista Brasileira de Enfermagem, 2018, v.71, n. 5, p. 2310-2315. https://doi.org/10.1590/o034-7167-2018-0044

MACÍAS NMR, et al. Terapia floral como modalidad terapéutica en el trastorno por déficit de atención con hiperactividad. Medisan. 2012; v.I6, n.Io, p.1533-1539.

MARTINEZ, Rosa L.; GARRIDO, Rosário M. Herpes zóster tratado con flores de Bach. A propósito de un caso. Rev Enferm, v. 37, n. 3, p. 45-8, 2014

MATOS, Dunia A.; GARCES, Maikel M. Efectividad de la terapia floral en pacientes con hipertensión arterial descontrolada. Medisan, 2014, v. I8, n. 8, p. I08I-1087.

MOREIRA, P. JUNQUEIRA, S. Reflexões sobre a prática profissional da terapia floral: relação teórico-prática e sua consolidação como prática integrativa complementar em saúde (PICS). 2017.

SALGADO, R. UTILIZAÇÃO DOS FLORAIS DE SAINT GERMAIN NO PROCESSO TERAPÊUTICO. 2010.

SALES LF, Silva MJP. Efeito das Essências Florais em Indivíduos Ansiosos. Acta Paul Enferm. 2012; v.25, n.2, p.238-242

SANCHES RCN. et al. Percepções de profissionais de saúde sobre a humanização em unidade de terapia intensiva adulto. Escola Anna Nery. jan./mar. 2016, v. 20, n. I, p. 48-54. 
Disponível em: http://dx.doi.org/10.5935/1414-8145.20160007. Acesso em: 30 de agosto de 2021.

SANTOS, MC.; TESSER, CD. Um método para a implantação e promoção de acesso às Práticas Integrativas e Complementares na Atenção Primária à Saúde. Ciência \& Saúde Coletiva, 2012; v. I7, n. II, p. 3011-3024.

SCHEFFER M. Terapia Floral Original do Dr. Edward Bach para Autoajuda: o livro básico compacto. São Paulo: Pensamento; 2008

SILVA NCM, et al. Estratégias de ensino das terapias alternativas e complementares na graduação em Enfermagem: revisão integrativa. Rev eletrônica enf. 2013; v.15, n.4, p.ı611067.

UNESC - Disponível em: http://www.unesc.net/portal/blog/ver/22/30470. Acesso em: 30 de agosto de 202I.

THALER K, et al. Bach Flower Remedies for psychological problems and pain: a systematic review. BMC Complement Altern Med. 2009. v.9, n.I6

VARGAS, DANIELA FINATO DE. Uso de Florais de Bach como prática integrativa e complementar em serviços de saúde da Universidade de Santa Cruz do Sul. 2019

VEGA, Noraima C. et al. Effectiveness of Bach flower therapy in patients with chronic alcoholism. Medisan, 2012, v. 16, n. 4, p. 519-525

ZAMBONATO, R. NOGUEIRA, E. BASES CIENTÍFICAS SOBRE AÇÃO DOS FLORAIS QUÂNTICOS. 2020 